\title{
Developing a shared syllabus template as a living document of inclusive practices in a teaching and learning community
}

\section{Christel Lutz ${ }^{1}$, Livia M. Untaru' ${ }^{2}$, Merel M. van Goch ${ }^{3}$}

${ }^{1}$ University College Utrecht, Utrecht University, The Netherlands, ${ }^{2}$ Educational Sciences, Utrecht University, The Netherlands, ${ }^{3}$ Liberal Arts and Sciences, Institute for Cultural Inquiry, Utrecht University, The Netherlands.

\begin{abstract}
Inclusive teaching and learning is central to our educational mission. In this project, we used a whole-institution approach to make our institution's inclusive objectives concrete and specific. We aimed to develop ways to capture our own community's goals and objectives in a 'living document', a syllabus template in which insights from educational literature on diversity and inclusion are presented alongside the voices and practices of members of our own community of practice (CoP). We created the syllabus template by using the literature to list elements of inclusive design, inclusive delivery, inclusive assessment, and learning-focused syllabi, then identifying examples of those elements in syllabi of local experienced practitioners and deepening the good practices in interviews with the experienced practitioners. The final syllabus template presents authentic practices from local syllabi, with explanations of the relevance of those examples and reference to educational literature, links to teaching tools, and contact-information for individual colleagues. The shared syllabus template deliberately situates academic development within the practice of the local CoP. We found that even the most experienced practitioners find it challenging to work on inclusive practices, which is all the more reason to stimulate a collaborative approach.
\end{abstract}

Keywords: Higher education; inclusive pedagogy; good practices; syllabi; interviews; liberal arts and sciences education. 


\section{Introduction}

Diversity scholars bring growing bodies of evidence showing that inclusive practices in institutions of higher education breed quality (Nature, 2014) and there is widespread agreement with the objective to strive for inclusive practices in teaching and learning (Lawrie et al., 2017). Yet, diversity scholars also observe that the objective "remains elusive, and opinions on how to achieve it proliferate" (Lawrie et al., 2017) and that the implementation of diversity policies is hampered by specific ideas or fears (Wekker, Slootman, Icaza, Jansen, \& Vázquez, 2016). We see inclusive learning and teaching as central to our educational mission. Therefore, our aim was to make our institution's inclusive objectives concrete and specific, and to involve all members of our community in the discussion, specification, and implementation of these objectives.

We use Hockings' (2010) definition of inclusive learning and teaching: it "refers to the ways in which pedagogy, curricula and assessment are designed to engage students in learning that is meaningful, relevant, and accessible to all" (p. 1). She distinguishes four areas of focus: inclusive design, inclusive delivery, inclusive assessment, and institutional commitment to and management of inclusive teaching and learning. We underline the importance of a wholeinstitution approach (Lawrie et al., 2017): shared understanding and relationships between all stakeholders (faculty members, students, academic developers, and senior management) are central to the successful implementation of inclusive practices in teaching and learning.

Starting as a student-led project, we focused on the course syllabus: the artifact outlining the key structural elements of the course. The syllabus serves as a design tool, crafted and recrafted by the instructor in collaboration with members of the teaching team, academic developers, topic experts and with students. Well-crafted syllabi invite students to connect course content and learning activities to important questions and societal challenges, and to focus on learning goals and objectives rather than on content and rules (Palmer, Wheeler, \& Aneece, 2016). The institution's board of studies - the body formally responsible for curriculum design, delivery, and assessment - considers the most central parts of a course's syllabus before including it in the course offer.

We aimed to develop ways to capture our own community's goals and objectives in a 'living document', a syllabus template in which insights from educational literature on diversity and inclusion are presented alongside the voices and practices of members of our own teaching community. This syllabus template will not serve as an end-goal or manual, but rather as an intrinsically discursive document capturing the practice of the local teaching community, which we regard as a community of practice (CoP) - a group of people mutually engaged in a joint enterprise, with a shared repertoire (Wenger, 1998). Through its use, members of the CoP will continually engage with one another in a discussion of the ways in which inclusive education might be implemented. 


\section{The process of creating the shared syllabus template}

We created the shared syllabus template in three steps. First, using the literature, we listed which elements of inclusive teaching practices could and should find a place in the syllabus template. Second, we identified examples of those elements in 21 syllabi of 11 local experienced practitioners. Third, we contextualized and deepened those good practices in interviews with 6 of the experienced practitioners. The experienced practitioners gave consent for including parts of their syllabi.

\subsection{Criteria: which elements of inclusive practices should be included in the syllabus}

We searched the higher education literature on inclusive practices for practices that are advisable and feasible in the local context (1-3) and regarding the syllabus specifically (4). We translated the practices into elements that should be addressed in the syllabus. 
Table 1. Inclusive practices that can be represented in the syllabus. References describe the practices, not in all cases their representation in the syllabus.

1. Inclusive design (criteria based on Nelson Laird, 2011; Saunders \& Kardia, 2004; Mallinger, Gabbard, \& Starks, 2016; Boysen, 2012)

a. The syllabus presents a selection of materials that resembles the inclusion of multiple theoretical perspectives for each course topic;

b. The syllabus includes relevant contributions to the field made by researchers from varying cultural backgrounds;

c. The syllabus lists material that appropriately addresses the experiences of marginalized groups;

d. The syllabus presents activities that support the development of constructive dialog skills.

2. Inclusive delivery (criteria based on Boysen, 2012; Mallinger et al., 2016; Lee, Williams, Shaw, \& Jie, 2014; Kumar \& Wideman, 2014; Burgstahler, 2009; Nelson Laird; 2011; Lombardi, Murray, \& Gerdes, 2011)

a. The syllabus discusses the type of environment the instructor expects to create and expectations about how students should approach the course;

b. The syllabus invites students to meet with the instructor to discuss diversity, inclusiveness and special learning accommodations;

c. The syllabus encourages regular and effective interactions between students and the instructor and describes practices which ensure that communication methods are accessible to all participants;

d. The syllabus describes how classroom discussions can be used to learn how to engage with others, and learn through interaction;

e. The syllabus presents content in multiple formats, e.g., video and text, inviting students to choose;

f. The syllabus describes varied formal and informal teaching activities which allow students to engage with content in various ways.

3. Inclusive assessment (criteria based on Butcher et al, 2010; Burgstahler, 2009; Lombardi et al., 2011; Nelson Laird, 2011; Kumar \& Wideman, 2014; Lee et al., 2014)

a. The syllabus describes authentic and complex assessment components, not based on reproduction;

b. The syllabus describes feedback opportunities to foster learning prior to assessment;

c. The syllabus announces flexibility and accessibility of assessment practices;

d. The syllabus announces that students are assessed using multiple methods and tools;

e. The syllabus announces that students are supported to evaluate their own performance, e.g. through reflection assignments.

4. The learning-focused syllabus "(is) characterized by engaging, question-driven course descriptions (...); a focus on student success; and, an inviting, approachable, and motivating tone" (Palmer et al., 2016). See also Slattery \& Carlson (2005).

a. The syllabus invites interaction by including information about instructors' availability outside of class, regarding office hours, office location, and e-mail address;

b. The syllabus includes the course description that captures the idiosyncrasy of the instructor's approach;

c. The syllabus clearly lists the course goals, preferably using action verbs (e.g. evaluate, analyze, create), rather than passive or vague verbs (e.g., learn, recognize, understand);

d. The syllabus links the course objectives to assessment forms;

e. The syllabus includes a description of how grades are determined (e.g., rubrics, performance assessment criteria) and which role students have in setting these criteria;

f. The syllabus guides students in organizing their work across the semester;

g. The syllabus includes a statement about what makes the instructor passionate about the topic;

$\mathrm{h}$. The syllabus is itself a learning tool, inviting the reader to connect course content to topics and questions of relevance to (potential students);

i. The syllabus mentions University Support Services (e.g., tutorial services, counseling center, career services and writing centers). 


\subsection{Examples of good practices found in syllabi of local experienced practitioners}

Using the criteria listed in 2.1, we identified examples of inclusive teaching practices in the syllabi used by experienced practitioners in our teaching community. These quotes serve to illustrate these criteria in the voices of colleagues familiar to the entire community.

Criterium 2a\&d: "The success of this course is, to a very large extent, our shared responsibility; this entails the willingness to do collective work and engage in critical dialogues with others. (...) The conversation or disagreement can of course be passionate, but it has to stay respectful and responsible to the other person's ideas and sensitivities. Articulating ideas, listening and being attentive to difference is the goal."

Criterium 2c: "Also, asking questions in class can simply save a lot of time and effort trying to figure stuff out. You might find that you have been approaching the problem wrong all along or that there are more ways to find an answer to the problem."2e: "Dante Alighieri, Inferno (ca 1310), Cantos I-III; available at Princeton Dante Project as text and audio (English/Italian)."

Criterium 3e: "You write a piece of approx. 500 words in which you reflect on your writing and research skills, and what you have learnt in your first semester, drawing on the selfassessment form that you will fill out in class during the first week, and the goals that you will set yourself."

Criterium 4b: "(...) However, processes of decolonization, globalization and transnationalism, along with critical interrogation of dominant discourses, have led to greater visibility of 'peripheral' or 'marginalized' scholarship. The decolonization of the discipline has resulted in a critical and sometimes radical focus on cultures being studied, and to serious challenges posed to the politics of knowledge production in anthropology."

Criterium 4d: "The portfolio is related to the following learning objectives: $1,2,3,4,5,6,8$. The individual research paper is related to the following learning objectives: $1,2,3,4,5,6$. The presentation is related to the following learning objectives: $9,10 . "$

Criterium 4g: "But above all, as a teacher and educational scientist, I am passionate about sharing this love for the beautiful Arabic language. I am always looking for new ways of teaching and like to experiment with digital tools and games in my teaching. I'm happy to hear your experience and feedback on the course."

\subsection{Additional considerations from interviews with local experienced practitioners}

Six experienced practitioners from our CoP were interviewed to contextualize and deepen the material collected in the previous two steps. Interview questions were inspired by literature on inclusive teaching and learning, educational sciences more broadly, and 
professional development (Sciame-Giesecke et al., 2009; Neumann, 2009; Nelson Laird, 2011; Burgstahler; Mallinger et al, 2016; Opertti \& Brady, 2011; Hockings, 2010).

1. Summarize your efforts in terms of diversity and inclusion. Respondents mentioned efforts on decolonizing the curriculum in terms of content; by focusing on class dynamics through acknowledging various perspectives and differences; and by focusing on equity over equality.

2. Is instruction adjusted based on student performance? Respondents mention adjustments made based on different forms of formal and informal assessment of learning: either mistakes that students make, which are discussed in the feedback, or (for example) expressions of homophobic attitudes through papers, which are also discussed individually.

3. In which ways are students offered the opportunity to 'customize' their learning? Respondents allow students to choose flexibility of assessment; contribute to the reading list; choose their own essay topics; practice exams; request extensions; be involved in course design. Respondents are lenient with students with learning difficulties.

4. How do you prepare for classroom interactions on difficult topics? Respondents ensure class discussions allow for multiple perspectives; use smaller groups; carefully select materials that will stimulate discussion; reflect on one's own perspective; teach students to present in front of a diverse audience.

5. How is a supportive climate in the classroom encouraged? Respondents mention striving for an equitable classroom; using safe, small groups; building a trust pact between instructor and students; using guidelines for constructive dialogue; guiding conversations; using a ritual at the beginning of the class that creates a sense of community.

6. How is active participation encouraged? All respondents found this difficult. Some mention translating their passion for instructional design and creating diverse teaching activities; using a random picker to avoid the same students vocalizing their opinions; breaking students up in small groups; doing a discussion round at the end of each meeting.

7. Do you perceive diversity in the classroom as challenging or enriching? All respondents found it both challenging (to create a safe environment; to be vulnerable as an instructor; to deal with difficult topics; to deal with assumptions and prejudice; to find common ground; to deal with tensions in society and in the classroom; to handle confrontations; to change students) and enriching (to have diversity of different kinds in the classroom; to encourage students to express different perspectives).

8. How do you explore your own cultural and intellectual background? Some respondents mainly moderate discussions, teach students how to argue well and do not share their own opinions. Others use personal examples, making their positioning explicit. 


\subsection{The syllabus template}

The resulting syllabus template presents authentic practices from local syllabi (main text), with explanations of the relevance of those examples and reference to educational literature, links to teaching tools, and contact-information for individual colleagues (boxes on the right).
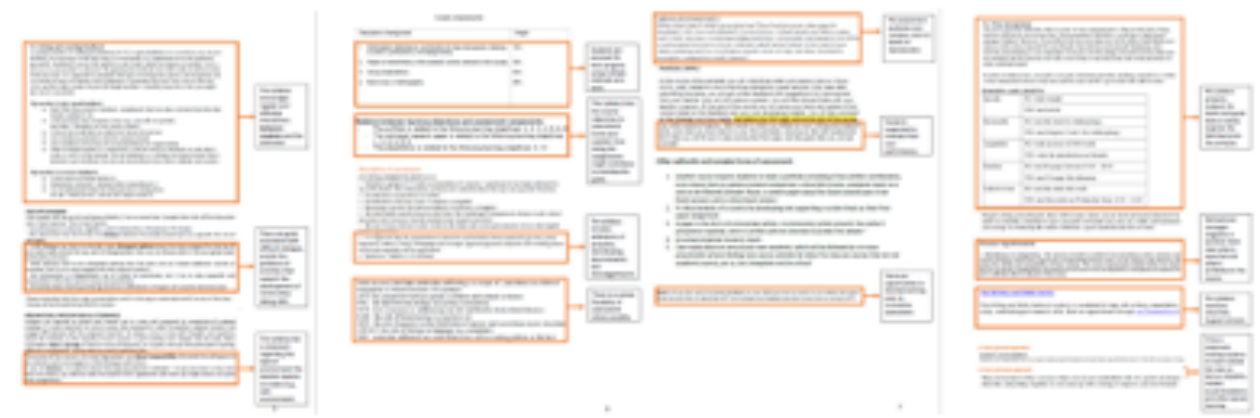

Figure 1. Pages of the syllabus template; details obscured because they are not relevant beyond our specific CoP.

\section{Discussion}

We explored whether the course syllabus can be used to specify, implement and discuss inclusive education objectives using a whole-institution approach. We discovered, first, that many inclusive teaching practices described in the literature can be meaningfully captured in a course syllabus. Next, a locally inhabited and interactive syllabus template was created by including examples of already existing practices in the words and voices of individual colleagues, alongside references to relevant educational literature and teaching tools.

We found that the collaboration on a shared syllabus template makes teaching practices explicit and visible, inviting all stakeholders to take part in their further development. It allows educational managers to promote an intrinsically discursive manner to work on inclusive education rather than bringing top-down initiatives. The shared syllabus template deliberately situates academic development within the practice of the local CoP. In this way changing needs and work demands (rather than, for example, policy initiatives) drive its learning (Boud \& Brew, 2013). The collaborative syllabus template is likely to impact students' learning in particular, as bringing learners into the construction of a syllabus creates a participatory practice that more effectively meets their needs (Jones, 2018).

Finally: inclusive education goes beyond making education accessible to all and diversifying the body of knowledge. It is a central matter for the quality of teaching and learning (Hanafin, Shevlin, Kenny, \& McNeela, 2007; Ladson-Billings, 1995). Through this project we learned that even the most experienced practitioners in our teaching community find it challenging to work on inclusive practices, which is all the more reason to support their work in more 
than one way, i.e. by working with educational and diversity experts, as well as - as proposed here - in ways that stimulate shared development within the local CoP.

\section{References}

Boud, D., \& Brew, A. (2013). Reconceptualising academic work as professional practice: Implications for academic development. International Journal for Academic Development, 18(3).

Boysen, G. A. (2012). Teacher and Student Perceptions of Microaggressions in College Classrooms. College Teaching, 60(3), 122-129. https://doi.org/10.1080/87567555.2012.654831

Burgstahler, S. (2009). Universal Design of Instruction (UDI): Definition, Principles, Guidelines, and Examples. In DO-IT. DO-IT. https://eric.ed.gov/?id=ED506547

Butcher, J., Sedgwick, P., Lazard, L., \& Hey, J. (2010). How might inclusive approaches to assessment enhance student learning in HE? Enhancing the Learner Experience in Higher Education, 2 (25).

Clifford, V. A. (2009). Engaging the disciplines in internationalising the curriculum. International Journal for Academic Development, 14(2), 133-143. https://doi.org/10.1080/13601440902970122

Diversity challenges (2014). Diversity [Special issue]. Nature, 513.

Hanafin, J., Shevlin, M., Kenny, M., \& Mc Neela, E. (2007). Including young people with disabilities: Assessment challenges in higher education. Higher education, 54(3), 435448.

Hockings, C. (2010). Inclusive learning and teaching in higher education: A synthesis of research. York: Higher Education Academy.

Jones, N. N. (2018). Human centered syllabus design: Positioning our students as expert endusers. Computers and Composition. Retrieved from https://doi.org/10.1016/j.compcom.2018.05.002

Kumar, K. L., \& Wideman, M. (2014). Accessible by Design: Applying UDL Principles in a First Year Undergraduate Course. Canadian Journal of Higher Education, 44(1), 125147.

Ladson-Billings, G. (1995). Toward a theory of culturally relevant pedagogy. American educational research journal, 32(3), 465-491.

Lawrie, G., Marquis, E., Fuller, E., Newman, T., Qiu, M., Nomikoudis, M., Roelofs, F., \& Dam, L. van. (2017). Moving Towards Inclusive Learning and Teaching: A Synthesis of Recent Literature. Teaching \& Learning Inquiry, 5(1), 1-13.

Lee, A., Williams, R. D., Shaw, M. A., \& Jie, Y. (2014). First-year students' perspectives on intercultural learning. Teaching in Higher Education, 19(5), 543-554.

Lombardi, A. R., Murray, C., \& Gerdes, H. (2011). College faculty and inclusive instruction: Self-reported attitudes and actions pertaining to Universal Design. Journal of Diversity in Higher Education, 4(4), 250-261. 
Mallinger, G., Gabbard, J., \& Starks, S. (2016). Managing microaggressions in the college classroom. Diversity and Inclusion in the College Classroom, 10.

Nelson Laird, T. F. (2011). Measuring the Diversity Inclusivity of College Courses. Research in Higher Education, 52(6), 572-588.

Neumann, A. (2009). Professing to learn: Creating tenured lives and careers in the American research university. JHU Press.

Opertti, R., \& Brady, J. (2011). Developing inclusive teachers from an inclusive curricular perspective. PROSPECTS, $41(3), 459$.

Palmer, M. S., Wheeler, L. B., \& Aneece, I. (2016). Does the Document Matter? The Evolving Role of Syllabi in Higher Education. Change: The Magazine of Higher Learning, 48(4), 36-47.

Sciame-Giesecke, S., Roden, D., \& Parkison, K. (2009). Infusing diversity into the curriculum: What are faculty members actually doing? Journal of Diversity in Higher Education, 2(3), 156-165.

Slattery, J. M., \& Carlson, J. F. (2005). Preparing an effective syllabus: Current best practices. College Teaching, 53, 159-164.

Saunders, S., \& Kardia, D. (2004). Creating inclusive college classrooms. A guidebook for University of Michigan graduate student instructors, 46-56.

Wenger, E. (1998). Communities of practice. Cambridge: Cambridge University Press.

Wekker, G., Slootman, M., Icaza, R., Jansen, H., Vázquez, R. (2016). Let's do diversity Summary report: the Netherlands. Retrieved from the University of Amsterdam, Diversity Commission. 